\title{
The geoscience profession's response to COVID-19 pandemic - An European Federation of Geologists' overview
}

\author{
${ }^{1}$ Independent consultant and EFG President, Ljubljana, Slovenia/Belgium; *Corresponding author, E-mail: m.komac@telemach.net \\ ${ }^{2}$ Independent consultant, Meggen, Germany \\ ${ }^{3}$ European Federation of Geologists, Brussels, Belgium \\ ${ }^{4}$ Collaborative Problem Solving Ltd, EFG past President, current EFG Treasurer, Gerrards Cross, United Kingdom
}

(Received: October 6, 2020; Revised accepted: May 20, 2021)

https://doi.org/10.18814/epiiugs/2021/021008

European Federation of Geologists (EFG) represents more than 45,000 professional geologists from 27 European countries and like other professions also geologists and geoscientists have been strongly affected by the COVID19 pandemic. One of the main purposes of EFG is offering support to its national associations being institutional constituents and their individual members, and based on this mission an assessment on the first impact of the pandemic was made in two steps. First, an on-line survey was performed to gather the framing issues for the virtual meeting at which representatives of national associations have elaborated on the responses and through the discussion formulated issues in more detail, suggested solutions and agreed on future measures to minimize the negative effects of the pandemic.

\section{Introduction}

\section{Background and Rationale}

In late 2019, an outbreak of pneumonia of unknown origin was reported in Wuhan, Hubei Province, China. Most of these cases were epidemiologically linked to the Huanan Seafood Wholesale Market (Ciotti et al., 2019). Detailed medical and biochemical analyses led to the isolation of a novel corona virus, SARS-CoV-2, previously named 2019-nCov (Zhu et al., 2020). Since the beginning of the epidemic in late December 2019, SARS-CoV-2 (now known as COVID-19) has now spread to 223 countries on all continents, and as of January 31 , 2021 (Update: 31 January 2021, 02:00 CEST), the WHO communicated 101,561,219 confirmed cases and 2,196,944 deaths globally (WHO, 2021).

The response to the pandemic was characterised by the imposition of restrictive measures, and programs of testing and tracing designed to prevent and/or slow the spread of the virus by governments around the world, including those by the European Union and its individual
Member States. Under the European Union subsidiarity principle, the European Union does not have the legal powers to impose health management policy or actions, such as quarantine measures or closing schools; these measures were in the domain of each of the Member States (Pankowska, 2020).

Accordingly, at the start of the pandemic in Europe in the first half of March 2020, most countries were tackling the pandemic-related challenges and risks in their own way, focusing primarily on socialdistance based restrictions that included introduction of advice to work from home if possible, wearing safety equipment (especially masks) during limited public activities, the closure of borders and banning of domestic and international travel, prohibition of large public gatherings, and implementation of testing and quarantine measures for infected persons and those who had been in close contact with infected persons. As the pandemic progressed, there was convergence in Member State responses, but the timing and nature of 'lock down' measures (also referred to as 'stay at home orders'), closures of significant parts of economies, and the approaches to testing varied across the EU. The timing and rapidity with which Member States are relaxing restrictive 'lock down' measures have also varied significantly. Against this background, the short-, medium- and potentially longterm consequences on industry, economy, and individuals varies significantly across the EU.

Impact on EU economy has been assessed by the Joint Research Centre and it indicates that a) the regional impacts diverse highly across EU (JRC, 2020a), b) the poorest households were affected the most (JRC, 2020b), and c) work from home can help tackle the negative effects, yet not for everybody (JRC, 2020c). These publications form the basis for the European Skills Agenda (EC, 2020a) that defines the strategy on EU recovery tools with focus on education capacities and strong links to four EC Communications, the European Green Deal (EC, 2019a, 2019b), the Digital Strategy (EC, 2020b), and the Industrial (EC, 2020c) and SME Strategies (EC, 2020d). Inclusion of the first two and the last EC Communication in the agenda for skills development relates clearly to confronting the challenges EFG Summit discussion defined.

This paper examines the particular impact of the pandemic on the 
geoscience profession in Europe, taking account of four defining characteristics:

1) The profession is diversified (GSL, 2020), providing critical services and support to a very wide range of sectors.

2) The nature of professional geoscience activities is also diverse, including office work, field work, teaching, public engagement, and attendance at national and international meetings (conferences, seminars, etc.).

3) Professional geoscience is delivered at a range of scales, from consultants, small and medium enterprises (SMEs), to large multinational companies and public sector institutions.

4) Although geoscientists are essential to national economies, many sectors of the geoscience profession are international and many projects are multi-national (both within Europe and across the world).

These specific characteristics give rise to a plethora of impacts of the COVID-19 measures on the geoscience profession in general and on individual geoscience professionals, and give rise to a need to examine these impacts and develop responses to increase resilience. This was the impetus behind the decision of the EFG to hold an online summit meeting of its member associations on 18th and 19th of June 2020 (EFG, 2020).

The 27 national associations of the EFG (Fig. 1) are membership organisations for professional geoscientists, with significant variation in membership numbers, size of office/secretariat, legal structure, and budgetary capabilities. Some of the national associations have professional secretariats, but others are run wholly by volunteers from the membership. Consequentially, their capacity to serve and support their members during crisis situations are diverse and this is particularly the case during the COVID-19 crisis. Although the national anti-pandemic measures make supporting national association activities from the EFG office (or other national associations) more challenging, the benefits of belonging to an effective pan-European support network at this time became more evident.

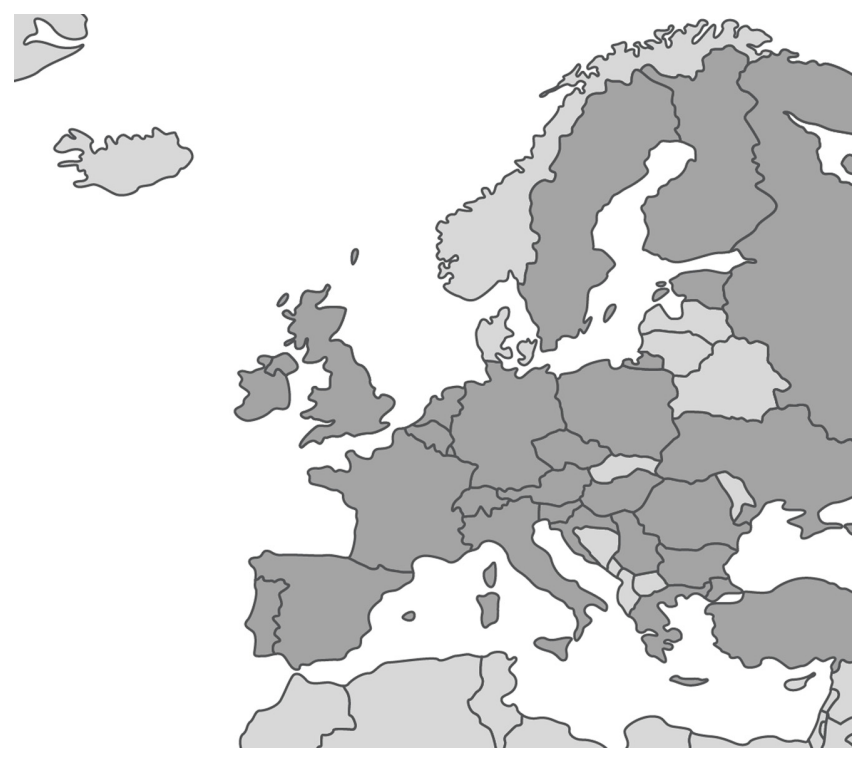

Figure 1. European Federation of Geologists consists of 27 membership organisations for professional geoscientists (members are shaded in dark grey; status from spring 2020).

\section{The Online Survey}

\section{The Process}

One of the principal pillars of EFG's mission and strategy (EFG Strategic Plan 2018-2022 - Towards a Sustainable Future; Developing and maintaining a strong EFG Member network; EFG, 2018) is to facilitate cooperation between the national associations in Europe that represent professional geologists and, with that, to enable the sharing of know-how, expertise and knowledge among its members. With this in mind, in April 2020, EFG launched a short survey to gather information from its members about the short, medium- and long-term impacts of COVID-19 on the geologic and geoscience profession at the national scale. Based on the data, collected on the national associations' status, the agenda and the content of a virtual summit devoted to COVID-19 responses in geological profession were set up.

\section{The Survey}

The survey consisted of 12 questions, mostly in the form of statements to which responders were asked to outline their agreement with a specific statement on a sliding scale of standard responses (e.g., "strongly disagree" (value 1), "partially disagree" (value 2), "partially agree" (value 3) and "strongly agree" (value 4). Answers in the scale from 1 to 4 have been assigned to the questions Q2d, Q2e, Q3b, Q3c, Q3d, Q4a in Q4b that are described in the following text. The questions and replies were grouped into four clusters:

1) Basic information - National Association information (membership numbers, etc);

2) Impacts on the profession:

Q2a) How is the geoscience world in your country reacting to this crisis?

Q2b) Is your association giving help or suggestions on how to deal with the crisis?

Q2c) What is the main effect, do you believe, this crisis is having on our profession?

Q2d) The current situation will come back to a new normal within three years. (Answer in scale 1-4)

Q2e) You believe the relationship between your individual members will be adversely affected due to the isolation period. (Answer in scale 1-4)

3) Impact on the work / market:

Q3a) How is the crisis psychologically and physically affecting the work of your membership?

Q3b) Is your organization continuing to work remotely? (Answer in scale 1-4)

Q3c) Your workload has changed due to the crisis. (Answer in scale 1-4)

Q3d) The job market for geologists will dramatically shrink. (Answer in scale 1-4)

4) Financial impacts:

Q4a) The revenue of your national association will drop significantly. (Answer in scale 1-4)

Q4b) It affects the European projects you participate in. (Answer in scale 1-4) 


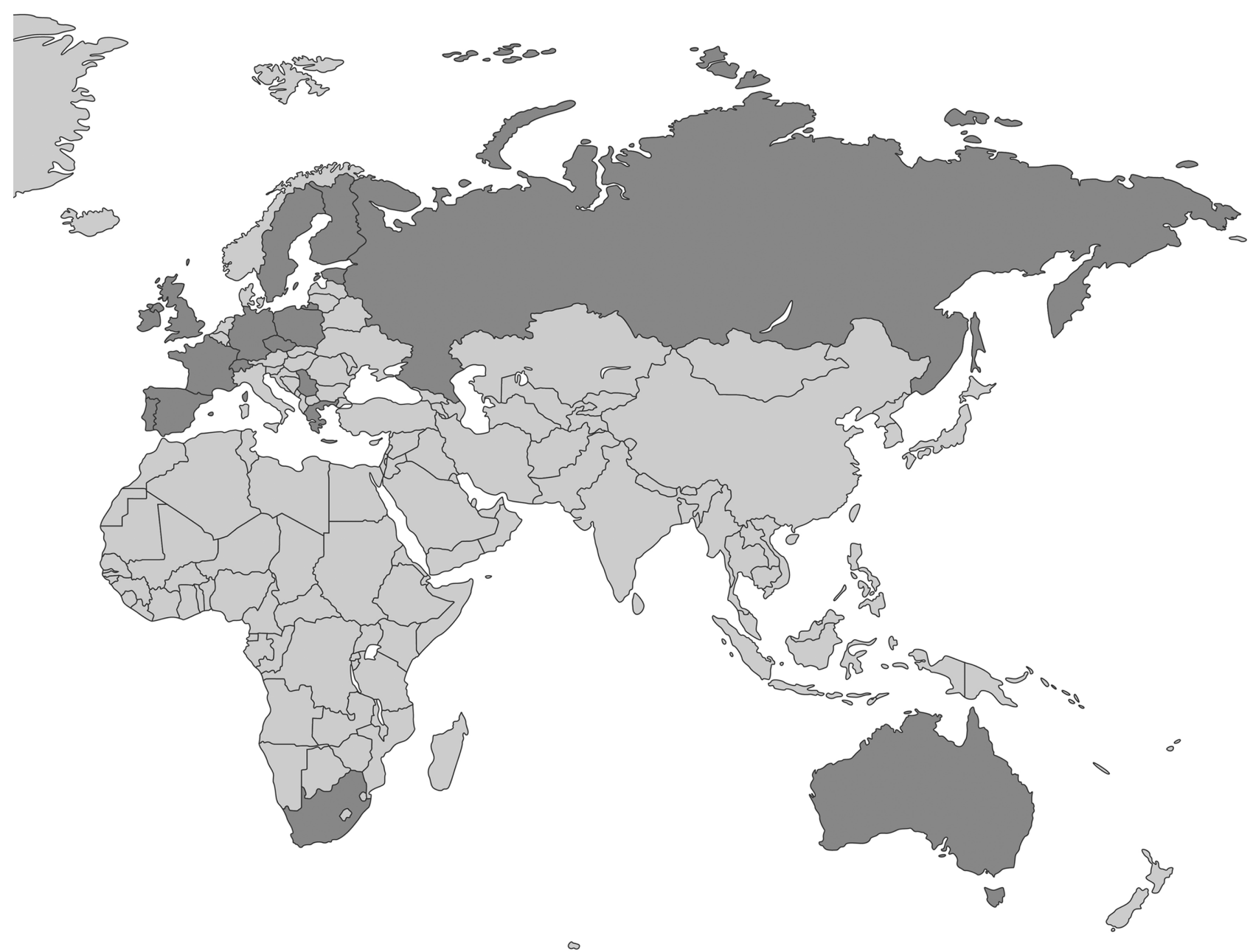

Figure 2. Geographical distribution of National professional geoscience associations that participated in the EFG survey on the impacts of COVID-19 on the geologic and geoscience profession at the national scale (participants in the survey are shaded in dark grey colour).

Out of the 27 national associations that are members of the EFG, seventeen $(N=17)$ participated in the survey with responses. In addition, six $\left(N_{\text {add }}=6\right)$ of them sent their feedback twice, at the beginning of the survey launch in April 2020 and an updated response a few weeks later. The updates provided us with additional value on the evolution of the situation and in regional perceptions in advance of the summit.

Out of 27 national associations that are members of the EFG, 15 from Europe (Czech Republic, Estonia, Finland, France, Germany, Greece, Ireland, Poland, Portugal, Russia, Serbia, Spain, Sweden, Switzerland and UK) and two affiliated associations, from Australia and South Africa participated in the survey with responses (Fig. 2). In addition, six of them, Finland, France, Germany, Spain, Switzerland and UK, have sent their feedback twice, at the beginning of the survey launch in April 2020 and few weeks later, as the situation developed. This gave us an additional value on the evolution of the situation and in the regional perception.

\section{EFG COVID-19 Summit}

Based on the survey responses, a concept for a virtual (on-line) meeting, devoted to the COVID-19 crisis in the geological and related Earth sciences in Europe was developed by the EFG. The so called Geo-COVID19 Summit was organised in mid-June 2020. Eighteen representatives of EFG's national associations participated in the event, which took place over two half-days. The event was structured in three segments/sessions.

The opening session sought to address the framing question: What are most difficult factors we are facing in this crisis? In this session, the current status of EC response to COVID-19 outbreak was examined, together with an overview of the EFG's response and presentation of the reports from the national associations, building on their questionnaire responses. Combining these three aspects was an excellent basis for discussion of the framing question, and the focus of the presentations and discussions was on the impact of COVID-19 on the following three topics:

1) the functioning and effectiveness of national associations;

2) the employment prospects for geologists/geoscientists; and

3) the future of the profession.

The second day focused on identifying opportunities, designing solutions and responses and sharing best practices. This session was also split into three interrelated topics consistent with the structure of the first session discussions: 
1) supporting the functioning and activities of national associations;

2) safeguarding and developing employment opportunities; and

3) challenges and opportunities for the future of the geological/geoscience profession.

The concluding session consisted of a series of mini-inspiration pitches from EFG staff introducing some initial and basic ideas on next steps. These included ideas on specific support services in response to the crisis, a digital response to COVID-19 and EFG office resilience measures, finding future funding opportunities (i.e., Horizon Europe, LIFE, COST, EIT, foundations, etc.), addressing the challenge of raising individual member numbers at national associations and maximising EFG's communication function.

The virtual meeting concluded with a question and answer session and the discussion on the next steps, which are provided in the next chapters.

\section{Results and Discussion}

The results are presented in two parts; the national association survey responses creating a foundation for the second part that evolved from the discussion during the on-line meeting.

\section{The Survey Among National Associations}

The results are presented here grouped into the three clusters described above. First, the responses related to the impact on the profession are presented, followed by the current and predicted impacts on geologists' working lives. Finally, the anticipated financial impacts will be given. Some of the responses enabled basic analysis and this is also presented here. The results focus on the first-round responses $(N$ $=17$ ), while additional responses from the second (repetition) round $\left(N_{\text {add }}=6\right)$ are not included, unless it's stated otherwise.

\section{Impacts on professional work}

In their responses to the question (Q2a), seeking to understand how the geoscience community is reacting to, and affected by, this crisis, all agreed there was a sudden and general slowdown in academic and industry activity since the crisis began. However, all also feel that the adaptation to online, remote, working has been quite fast. Employers have adapted field-based working practices by reducing the number of personnel on site to ensure compliance with rules imposed by governments, and staff have been permanently or temporarily laid off. Similar trends have been detected in US (Gonzales and Keane, 2020a, $2020 \mathrm{~b}$ ). One of the most negatively affected communities in terms of available work and income are self-employed (freelance) geoscientists for whom government support is limited or non-existent and whose clients have retrenched.

When asked whether the individual association is giving help or suggestions to its members on how to deal with the crisis (Q2b), eight associations (47\%) reported that they haven't taken any special actions, since they have small capacity and the general work conditions for geologists, did not require such action. Nine associations (53\%) are providing and giving online seminars and focusing on increased remote exchange of information. Alongside these actions to take normal activities online, some associations are increasing the support they offer to members on financial and psychological issues, and providing help interpreting government guidance related to COVID-19 restrictions and behaviour as it applies to geoscientists.

Views on the main effects that this crisis is having (and is likely to have) on the sectors that employ geoscientists (Q2c) were largely aligned. Nine associations (53\%) reported that they expect that there will be significant redundancies and the outlook for short-term job creation was pessimistic. Sectors that have been particularly badly affected by contraction in the labour force include oil and gas (already in decline before the COVID-19 crisis; i.e., CIEL, 2020; IEA, 2020; Macrotrends, 2020; Rystad Energy, 2020), mining and construction industries; these are industries that typically involve travel and sitebased work for geoscientists. Similar, yet not so dramatic, trends for the subsectors of oil and gas and the mining have been detected in US (Gonzales et al., 2020). On the other hand, where the workload is suitable, home/tele-working has been found to be an effective and feasible way to work for many geoscientists.

In response to the question about whether the situation will normalise (a new normal) within three years (Q2d), 71\% $(\mathrm{N}=12)$ of the responses considered that the situation is likely to return close to or completely to normal in relation to the pre COVID-19 crisis. None of the responses thought that the current situation would remain constant (or more negative) in the next three years, although $29 \%(\mathrm{~N}=5)$ replied that the situation is not likely to return back to the situation prior to the COVID-19 crisis.

When asked whether they believe that the relationship between individual members and their national association will be adversely affected due to the isolation period (Q2e), more than half of the associations $(\mathrm{N}=9 ; 53 \%)$ don't think there will be any problems at all, $24 \%(\mathrm{~N}=4)$ that there won't be any major problems among their individual members, while $24 \%(\mathrm{~N}=4)$ believe there will be adverse to notably adverse effects due to the isolation.

\section{Impact on geoscientists' working conditions}

In relation to potential impacts on the working conditions of geoscientists, participants were asked to respond to a question about whether the crisis is psychologically and physically affecting the work of individual members (Q3a). Eight responders did not consider this to be a major effect on the membership. Nevertheless, whilst people still value the human contact and face to face events, the transition to remote work and virtual meetings has been reported to be a reasonable substitute during the lockdown, especially given the uncertainties related to the virus, more people are afraid of losing their jobs.

When asked whether the national associations will continue to work remotely $(\mathrm{Q} 3 \mathrm{~b})$, all of them confirm that they continue their work by using virtual tools and remote means of work (i.e., tele-working, working from home) for the foreseeable future.

The participants were asked about changes in geoscientists' workload due to the COVID-19 crisis (Q3c). The majority of the participants $(\mathrm{N}=11 ; 65 \%)$ report that workload has already changed significantly or to some notable degree due to the crisis. Unfortunately, the question didn't include the option on whether the change was towards more or less workload. Based on individual parallel and unofficial discussions the assumption of the authors is that the workload increased. Due to 
the fact that people no longer have a commute to the office they fill that time with work. It is likely that changes to workload and productivity (positive and negative) is significantly affected by working from home and individual geoscientists' domestic circumstances. Many individuals have had to fit their work around child care responsibilities as well as teaching their children who also stayed at home; the availability of space in the home for working and participating in meetings has also been a significant challenge for many. Present is also the phenomena of the "Zoom fatigue" (Lee, 2020), excessive screentime, lack of real social interactions, reduced physical movement, all of which clearly make people feel exhausted (reported during the live discussion).

When asked for views about the anticipated changes in the job market for geologists and geoscientists, with focus on potential shrinking of it (Q3d), the opinions were more spread. Fewer than half of the survey participants $(\mathrm{N}=8 ; 47 \%)$ partially or totally agree that there is a chance the market will be reduced, while the rest $(\mathrm{N}=9 ; 53 \%)$ believe that this will not happen or there's a small chance it could increase. For comparison, Gonzales et al. (2020) performed a more temporally defined (April-June 2020) analyses that was focused on small businesses in the oil and gas, and mining sectors in the US. Their results indicate that the large negative effects on business due to the COVID-19 crisis are decreasing in the observation period, while at the same time this decrease most probably contributes to the increase of the moderate negative effects.

The above results indicate that the negative effects due to the COVID-19 crisis are less dramatical as they appeared at the beginning of the pandemic, yet they are still present and they need to be regarded with caution, also in Europe.

\section{Financial impacts}

One of the effects of the COVID-19 crisis will inevitably also be economic crisis. In this regard, the national associations were asked whether they envisage that the revenue of the association will drop significantly (Q4a). Almost two-thirds $(\mathrm{N}=11 ; 65 \%)$ of the respondents expect their association revenues should not be affected, at least in a dramatic way, while the rest $(\mathrm{N}=6 ; 35 \%)$ expect that the revenues would drop notably or significantly.

When asked about the impacts of the crisis on the European projects that national associations participate in (Q4b), more than half $(\mathrm{N}$ $=9 ; 56 \%$ ) of national associations are convinced that the EU projects on which they work will not be affected, or not significantly. On the other hand, $44 \%$ of responses $(\mathrm{N}=7)$ indicate that they expect a considerable effect (reduction) on their work related to the European projects.

\section{The EFG COVID-19 Summit Outcomes}

During the virtual meeting, the challenges considered in the questionnaire formed the framework for the core discussions. For each of the three challenges, initial framing questions were presented that would ease, "provoke" and facilitate the development of the group brainstorming and formation of ideas on potential solutions and further steps.

\section{Initial questions for the emerging challenges}

Related to the impacts on functioning and activities of national associations, the initial questions focused on challenges related to addressing the reduction or complete lack of face to face contacts/communication, potentially reduced functional capabilities of the national association's office/secretariat, potentially reduced or cancelled previously planned activities and development of new or novel ones, in addition to overcoming the challenges of organising international meetings.

Impacts that could affect the employment prospects for geologists focused on identifying which of the geo-employment sectors are likely to see the most business failures in COVID-related recessions and what is expected level of unemployment that could be related to these failures. Here under the term failures the following results are meant: insolvency or closure of the company, or loss of business/projects that lead to staff redundancy measures. In common with significant economic and other changes, it was considered that the post COVID-19 economic landscape could offer new opportunities. In relation to this, several valid questions emerged, for example which organization types (e.g., SME, multi-nationals) are likely to be most adaptable to the post-COVID economic landscape. There was also discussion of whether the positive environmental impacts manifested during the lockdown (especially air quality and $\mathrm{CO}_{2}$ emissions) will lead to new employment opportunities in renewable energy, climate change adaptation and other environmentally more friendly sectors and consequentially, what transferable skills and technologies will be most valuable to geologists navigating the new employment landscape for each career stage. Further, we were then keen to learn about the extent of the impacts that the recession and consequently the introduction of new "COVID-safe working practices" (e.g., remote working) could have on the quality of the geologists graduating process and the recruitment process of these graduates. In addition, we were interested also in the changes in other areas. These were the retention of mid-career geologists, the limited career progression opportunities related to reduced or limited availability of supervision, mentoring, continuous professional development (CPD) and acquisition of relevant and varied experience.

Within the final group of initial questions, we asked the participants about the impact of the crisis will have on the future of the profession. These addressed the form and extent of the potential effects of the crisis on the geological profession, ranging from the personal protective equipment used; ability to work "COVID-safely" in the office, underground or in the field; the reduced or impossible access to the overseas projects; ongoing lack of professional and official face to face communications (including and especially informal networking); the safety of travelling abroad for work and potential risks that exist on return; the issues with obtaining suitable medical insurance when travelling for work; and finally whether parenting (baby-sitting or teaching) or other caring responsibilities (i.e., for vulnerable family members) are compatible with working from home.

\section{Discussion, developed ideas and solutions}

Based on the national association online survey responses three challenges had been identified for Summit discussion: the impact of the crisis on the operation of national associations, the impact of the crisis on employment prospects and the expected changes of the 
future work conditions, and it was envisaged that they would be considered one after the other. However, it was evident that the three (artificially created) domains are inter-related, and consequentially the discussion developed in addressing all three at the same time, which resulted in an interesting and productive debate. Nevertheless, the outcomes and with that the potential solutions could finally be grouped in four groups:

1) General outcomes of the discussion,

2) Outcomes of the discussion on the need for and nature of EFG support to the national associations,

3) Outcomes of the discussion on the employment prospects, solutions for safeguarding and developing employment opportunities, and

4) Outcomes of the discussion on the current and future impact on and the future meaning of the geological profession.

\section{General outcomes of the discussion during the summit}

There was a wide range of experience among the summit participants of the current situation and comprehension and adaptability to its effects. There was agreement that extrovert people have tended to crave for personal contacts more, while introverted individuals have adapted more easily to home and 'virtual' working. It is clear that, even where adaptation has been relatively smooth, feelings of isolation have been common and there is concern that this could be a trigger for other, potentially longer term, psychological problems. Indeed, these problems are not unique to the geological profession, as they can be observed in the wider society (Panchal et al., 2020). The summit participants agreed that the new home-based working conditions require a range of computer, virtual and social media communication literacy and skills, and for mainly in older generations this was and still is a challenge. However, based on the reports received and participation in virtual events, the participants felt that the adaptation to the new communication landscape was broadly successful, or at least manageable. Another frequently reported challenge is the lack of physical movement during the working day and the absence of a 'journey to work' leading to being glued to the computer screens for longer periods than when working at the office. There was a clear expression of a strong need and necessity among participants to include the natural breaks into the working routine that is a usual part of the non-digital world/work environment. In addition, by working at home, the critical social component of being at work diminishes and the live communication skills weaken, hence there may be some transitional period to overcome the return to a lively and noisy environment. The length and nature of this transition is likely to vary greatly from individual to individual. On the other hand, the general impression in the discussion was that the return to offices will provide respite for some if individuals' home working conditions were sub-optimal (lack of space, lack of privacy and distractions from children and others needing care) and will hopefully help reinvigorate the osmosis of knowledge sharing with junior staff and the benefits of networking that are so key to their development. As similar challenges of working from home was defined also by the International Labour Organization, they have published guidelines for employers that tackle these newly emerged challenges at the organizational level (ILO, 2020a, 2020b), while others prepared guidelines for employees that deal with individual challenges of maintaining mental health and well-being when working from home (APAF-CWMH, 2020).

\section{Summit outcomes and the recommendations - help to national associations}

Summit provided a useful platform to define the needs and the nature of support national associations require in the future. The EFG organisation through its services, platforms, tools, and networking capacities, could provide to the national associations, there was consensus among national associations that tighter and two-way cooperation was considered to be the optimum approach. Like EFG, its member organisations are learning how to deal with the daily challenges of the situation, especially virtual meetings, and also to confront them in an innovative way. At the start of the crisis, organisations were initially trying to replicate physical meetings but have soon learned that all day meetings have proven not to be productive and exhausting. The solution of splitting them into several consecutive days of shorter sessions, not lasting more than an hour and a half, is much more productive and bearable and a key learning point has been the value of detailed preparation. Another challenge is the international meetings where participants are located in the various and also very different time zones, which usually means that some participants are attending at very late or extremely early hours.

Experiences from the past several months of the lockdown have shown that there was an increase of participation in webinars and online conferences and training courses and the reasons for that may vary. Either the participants have more time for education, they crave for new perspectives, or there's a great ability to devote time to these types of virtual meetings in comparison with the demanding online meetings that require intense concentration.

It is generally still felt that face to face meetings are preferable due to easier communication, the possibilities of networking during regular breaks (especially informal chats and chance meetings), social events (dinners and the like) before and after formal sessions, and finally not being sat for hours at a time and at the same time looking at a computer screen for a long. Whilst the risk of being exposed to the COVID-19 during travelling is still high, and during the period of heightened risk until the pandemic indicators are reduced, this will be the model. However, when the 'new normal' is established, more meetings and conferences are expected to take place online reducing travel costs and time, and those that do happen in-person are expected to be of a hybrid nature where those who cannot travel can participate remotely.

Having excellent technical capabilities and knowledge, EFG is well placed to act as a central repository for various national educational materials such as online trainings, courses, webinars, etc. and these could be translated and offered to other members. This cooperation would act to connect the membership more fully with each other. In relation to mentoring, coaching and training activities several associations have solid experiences in these fields and the lockdown is a suitable period to share virtual knowledge, know-how and expertise transfer to those that want to benefit from them. For those who are under-engaged or permanently or temporarily laid off, there's also room to improve linguistic, managerial, public communication, IT and financial reporting skills, as there's usually too little time to advance these skills during 
regular work activities; EFG can facilitate sharing of programs and opportunities for this kind of learning. The most important asset that the EFG has is its well-established network between national associations of geoscientists within Europe, and very good cooperation with sister associations internationally, outside Europe. Consequentially, EFG will intensify its activities as a conduit for analysing and making available collective resources and as a facilitator/platform of the knowledge sharing. Along with more "technical" expertise, assistance coaching and guiding activities should also include support to confront and combat the psychological challenges, stress, shock, fear and anxiety related to the notable changes in work, life style, and job and financial insecurity.

\section{Summit outcomes and the recommendations - employment issues}

Summit also thoroughly addressed the employment prospects, solutions for safeguarding and developing employment opportunities. It was a common assumption that different industries, which employ geologists and geoscientists will be affected differently by the pandemic impacts, either in mid- or in long-term. For example, extractive industries linked to the mining and quarrying have solid reasons to soon reopen facilities (although demand will be affected until construction and manufacturing recover), while oil and gas industry was already in crisis prior to the COVID-19 crisis (i.e., CIEL, 2020; IEA, 2020; Macrotrends, 2020; Rystad Energy, 2020), and the lockdown additionally affected sector covered this study with private and public transport being kept to minimum (Dixon and Gause, 2020; Intelligent Transport, 2020; Zhang and Hayashi, 2020). Anti-pandemic measures also severely hinder the activities on international projects and in many cases remote working has its limits.

Nevertheless, Summit participants believed there are huge opportunities and that harnessing the raised environmental awareness and the urging for a green recovery is an area where geologists and geoscientists can actively and productively contribute. Society will require expert help for the transition and geologists will be wise to transfer their skills and become more comfortable with commercial imperatives that will ultimately drive that change. Vice-versa, there are opportunities for the sectors (still) being regarded as environmentally damaging to shift/adapt their activities towards more environmentally friendly and greener technologies and turn their current vulnerability into positive contribution to the new green industries. Creativeness and innovation offer huge opportunities for entrepreneurship in developing and using novel approaches in digital technology, remote sensing (Earth observation), teaching, etc.

In the geoscience sector many of the services to the public and pertinent industries are provided by self-employed individual consultants, SMEs and larger consultancies. As this "modus operandi" (especially the self- employment model) enables faster adaptation to changes, it also represents much higher exposure to volatility of the industrial sectors to which the services are provided. In general (and mainly based on anecdotal observations), geoscientists are not natural entrepreneurs and, whilst levels of technical and scientific expertise are generally high, commercial skills are poorly developed or absent. An obvious solution for this during the coming recession is the development of appropriate training, coaching and mentoring programs in entrepreneurship and business administration to underpin adaptation to the new economic environment and the creation or retention of jobs in the geo-workforce. An interesting model that could assist in minimising the risks and consequences associated with unexpected conditions (such as pandemic) could lie in the formation of coalitions of selfemployed individuals and/or SMEs, joining expertise and resources in legal or non-legal formats to cooperate and to share business/entrepreneurship resources. Some examples of such cooperation are Co-operative Entrepreneurship (McDonnell et al., 2012).

Discussion participants feared that the isolation, anxiety, grief and loss of self-worth during the crisis could translate into lack of motivation for employees, panic-driven management styles, expectation of being constantly available, reducing (or even cancelling) professional development and team building programs. Along with loss of connection and the difficulties for employees identifying with organisations without regular in-person contacts with colleagues and superiors, all listed reasons could also represent huge risks to the future of geoemployment. The general agreement was that the hybrid solutions of home/office working practice and related changes will most probably transform and enhance the traditional "go to office" organisational arrangements. Responses to these big challenges are likely to differentiate the organisations that will adapt and thrive, retaining a motivated and successful workforce, from those who will shed personnel and potentially fail. The Summit saw solutions lying in recognising these challenges and, consequently promoting more compassionate, communicative and thoughtful relationships between employers and employees.

\section{Summit outcomes and the recommendations-impacts on profession}

The third topic addressed was the current and future impacts the COVID-19 will bring on the geological profession. Every profession develops through time and so does geology, especially in response to major societal shifts. There is significant hostility or aversion towards two sectors that employ large numbers of geoscientists because they are regarded as environmentally unsustainable (i.e., Ernst and Young, 2018, Hahn-Griffiths, 2019; Lacey et al., 2019; Campbell et al., 2020; Jamasmie, 2020). These are mining and quarrying and fossil fuel extraction. In relation to fossil fuels, the pressure is towards a transition to greener technologies and approaches, including development of alternative energy sources like hydrogen and geothermal energy, and mitigating carbon dioxide emissions by carbon capture, utilisation and storage. In mining and quarrying, innovation is needed to reduce to a minimum the amount of primary raw material extracted, move towards a circular economy, and move towards a new responsibility in mining whereby its impacts are reduced as far as possible. There are significant challenges in transforming these sectors and, whilst they are already modernising and becoming less and less environmentally damaging, there is still much work to be done, much of it including geoscientists. If geoscientists with traditional roles in these sectors fail to adapt and acquire new and transferrable skills and expertise, this will impact adversely on their employment prospects. The upcoming period of disruption and recession therefore presents an opportunity for training and professional development, particularly in these sectors.

Automation, computerisation/digitalisation (super computers, data 
mining, artificial intelligence, processing and modelling (i.e., Deloitte, 2017, 2020; Ernst and Young, 2018), novel Earth observation techniques (e.g., drones, 3D scanners and micro satellites) and robotics are increasingly featuring in geological sphere to enhance or replace person hours. In the case of critical situations, such as the COVID-19 pandemic, such automated and semi-automated technologies can ease the difficulties of restricted travelling and facilitate the challenges of acquiring qualitative field data. However, in-situ work and real ground data collection will always be a quintessential part of the geological field work and cannot be eliminated. There is an opportunity to develop hybrid models that apply technology to minimise the field work and potential exposure to risks whilst retaining the essential "ground truthing" for which geologists are uniquely qualified and ensuring that subsequent generations learn these fundamental skills.

Due to the travel restrictions, some geologists have found that maintaining the CPD requirements associated with their professional titles (e.g., EurGeol, CGeol, PGeo), either because they have been laid off (permanently or temporarily) or because the work they do depends on international travel and has been interrupted. EFG is adapting its CPD requirements on a case by case basis where individual geoscientists are temporarily unable to meet the CPD requirements. On the positive side, there have been many opportunities to attend online courses and conferences suitable for CPD (often free of charge) during the pandemic.

Working from home brings several unpleasant implications that may make it unsustainable in the longer term for many people. These include:

1) not being able to separate "office" from home,

2) lack of privacy, competition for suitable working space with other family members, especially in smaller homes, and constant distractions by family members with consequential negative effects on family life,

3) employers' expectation that workers will be available at all times, leading to exhaustion and burn-out, whilst resulting in higher working hours than when working at the office, and

4) lack of face to face communication.

In addition, symbiotic relationships that are built with colleagues during office work are disappearing. For younger professionals that haven't yet secured their own living environment achieving peaceful and productive working space is even more challenging, and if they live alone, isolation and mental health impacts are a serious problem.

\section{Three Major Problems and Challenges}

Whilst national and international responses to the pandemic have undoubtedly had huge and immediate impacts on economies and the wellbeing of citizens, they have also thrown into sharp focus three major problems and challenges the modern world is currently facing.

The first of these challenges is related to the climate crisis and the twin needs for measures to take actions that will reduce emissions of greenhouse gases as well as developing adaptation and resilience measures to respond to the inevitable effects of the warming that has already taken place. The reductions in economic activity during the pandemic gave rise to measurable reductions in warming gas emissions and markedly improved air quality in cities; as we relax restrictions in Europe and elsewhere in the world, the question is whether we can re-start economies without throwing away these improvements. The expectation is that Europe will aim for (and invest in) a green recovery and geoscientists will have a pivotal role to play both in the acceleration of decarbonisation and in the innovative measures that will be needed to build resilience and climate change adaptation into engineering and spatial planning. This is an important growth area for geoscience employment and it is easy to see that transferable skills from the oil and gas industry will be extremely valuable to achieve the energy transition.

The second challenge is related to the social justice and diversity issues that society has been neglecting in the past, and which are reflected in the workplace (including the geoscience profession). Gender, racial, social, political and religious diversity will need to be more embedded into the business landscape of the geoscience sector in the future, and activities in this direction are already ongoing in the form of international projects, regular webinars and ethical frames being developed.

The third challenge relates to the probability of further pandemic outbreaks of diseases not currently known to humanity and this challenge is the least predictable. It represents a form of new reality that, as we are experiencing now, can drastically change life to its core and affect the profession substantially. The COVID-19 has acted as a testbed for addressing future such occurrences and it showed (and is continuing to show) the deficiencies and advantages of geological sector and profession. Returning to the four characteristics of the geological sector and profession, as defined in the beginning - the wide range of customers varying also in scale ( 1 and 3 ), and the diverse nature of activities that include different working environments including travelling ( 2 and 4 ), it's rather obvious that this sector may not be affected by the COVID-19 related changes with the same effects. While some areas, such as field work related to travelling, practical educational courses (i.e., laboratory courses) and public related activities are more affected, while domestic field work (where allowed), office work, performed from "home office" is still feasible (but potentially hindered when a person has children) and attending mostly free of charge online courses, conferences and meetings are less affected or have adopted to the new circumstances. The most notable positive development can be attributed to the rather effective shift towards the digitalization and operationalizing several activities such as meetings, lecturing activities, processes modelling in the virtual world/reality, and obviously less time spent for daily commuting. Still, it has to be pointed out that especially physical-work related activities could not adopt due to the nature of it - actual data gathering in the field. In the mid- and long-term the most notable positive effects of the COVID-19 pandemic on the geological sector could be the consequential swifter societal and economical shift from brown to green economy. Such transition (also called the Green New Deal; The Conversation, 2020) would force some domains of geological profession, such as oil and gas, and fossil fuels related mining into change and adaptation towards more greener research and exploration activities. The imminent positive effects of the industrial slow-down due to the COVID-19 are visible also in the lower environmental impacts (i.e., Figueres, 2020; Le Querere et al., 2020; Zalasiewicz, 2020), which hopefully will set new foundations for the future where "the pandemic acts as a catalyst to change society's planetary impact, such as by decarbonising industry across the world" (Zalasiewicz, 2020). An important factor that will facilitate this 
process in a positive direction is geoethically responsible management of the Earth system and this will only be possible with shifting away from both traditional practices by the industry and traditional perceptions by the society, starting with the education for sustainability that will provide the humanity with the tools we need to address the full complexity of the urgent environmental concerns (Vasconcelos and Orion, 2021). Other recent contributions to discussion on geoethics and the future development of geoscience also strongly support these challenges, both in relation to the traditional geo-professional topics and in relation to much wider sustainability challenges as a consequence of the "anthropocene" (Marone and Bohle, 2020; Peppoloni and Di Capua, 2020).

\section{Conclusions}

Like all other sectors of the European economy, the geoscience professions and the sectors they serve were affected severely by the COVID19 pandemic, impacting all branches and at all levels; consultancy, SMEs, NGOs, geoscience organisations and international companies.

It is to be hoped that lessons learned during this pandemic will ensure far greater global resilience and preparedness for any similar future occurrences. The geoscience profession will survive this shocking and challenging period, but it is imperative that we build on our observations and learn to drive adaptability and innovation. Only with such an approach, a greater societal resilience can be achieved and to maximize its success, a solid support of geoethically responsible management, proper societal education, and finally, availability of mechanisms and tools that could be relatively easy to implement and use are essential.

\section{Acknowledgements}

Authors would like to thank all the representatives of national associations that have taken the time to submit the replies to the survey and to actively participate at the EFG COVID-19 Summit session. Also, authors are grateful to Editor-in-Chief Prof. Dr. Jin-Yong Lee and enormous reviewers for their constructive comments and suggestions.

\section{References}

APAF-CWMH, 2020, Working Remotely During COVID-19: Your Mental Health and Well-being. American Psychiatric Association Foundation, Center for Workplace Mental Health, Washington. http://workplacementalhealth.org/getmedia/fd8a9b98-b491-4666-8f27-2bf59b00e475/ Working-Remotely-During-COVID-19-CWMH-Guide [accessed 5th January 2021].

Campbell, R., Tivey, J., and Wright, O., 2020, Mining and Metals 2020: ESG front and center. White and Case LLP, New York. https:// www.whitecase.com/publications/insight/mining-metals-2020-esg-frontand-center [accessed 2nd December 2020].

CIEL, 2020, Pandemic Crisis, Systemic Decline: Why Exploiting the COVID-19 Crisis Will Not Save the Oil, Gas, and Plastic Industries. Center for International Environment Law (CIEL), Washington, 28 p. https://www.ciel.org/wp-content/uploads/2020/04/Pandemic-Crisis-Systemic-Decline-April-2020.pdf [accessed 2nd December 2020].

Ciotti, M., Ciotti, M., Angeletti, S., Minieri, M., Giovannetti, M., Benve- nuto, D., Pascarella, S., Sagnelli, C., Bianchi, M., Bernardini, S., and Ciccozzi, M., 2019, COVID-19 Outbreak: An Overview. Chemotherapy, v. 64, pp. 215-223. doi:10.1159/000507423

Deloitte, 2017, The digital revolution: Mining starts to reinvent the future. Deloitte Insights series, Deloitte Development LLC, Deloitte Touche Tohmatsu Limited. https://www2.deloitte.com/content/dam/Deloitte/ global/Documents/Energy-and-Resources/deloitte-au-er-digital-revolution.pdf [accessed 2nd December 2020].

Deloitte, 2020, Tracking the trends 2020. Leading from the front. Deloitte Touche Tohmatsu Limited. https://www2.deloitte.com/content/dam/ insights/us/articles/tracking-the-trends-2020/DI_Tracking-the-trends2020.pdf [accessed 2nd December 2020]

Dixon, S., and Gause, M., 2020, Understanding COVID-19's impact on transport organizations. Guidance for transportation leaders. Deloitte Touche Tohmatsu Limited. https://www2.deloitte.com/content/dam/ Deloitte/za/Documents/public-sector/za-COVID-19-Transportationsector.pdf [accessed 2nd December 2020].

EFG, 2018, EFG Strategic Plan 2018-2022 - Towards a Sustainable Future: European Federation of Geologists. European Federation of Geologists. https://eurogeologists.eu/wp-content/uploads/2018/10/2018_2022_strategy_public.pdf [accessed 5th July 2020].

EFG, 2020, EFG online COVID19 Summit: European Federation of Geologists. European Federation of Geologists. https://eurogeologists.eu/ efg-online-covid19-summit/ [accessed 5th July 2020].

Ernst and Young, 2018, Top 10 business risks facing mining and metals in 2019-20. EYGM Limited. https://assets.ey.com/content/dam/ey-sites/eycom/en_gl/topics/mining-metals/mining-metals-pdfs/ey-top-10-business-risks-facing-mining-and-metals-in-2019-20_v2.pdf [accessed 2nd December 2020].

Figueres, C., 2020, Covid-19 has given us the chance to build a low-carbon future. The Guardian. https://www.theguardian.com/commentisfree/2020/jun/01/covid-low-carbon-future-lockdown-pandemic-greeneconomy [accessed 2nd January 2021].

Gonzales, L., and Keane, C, 2020a, A National View of Geoscience Workforce Changes during COVID-19. Using federal data sets to examine COVID-19 impacts on the geoscience workforce. American Geosciences Institute, Alexandria, US. https://www.americangeosciences.org/sites/ default/files/DB_2020-013_rev20201119-COVID-FedDataEmploymentUnemployment.pdf [accessed 2nd January 2021].

Gonzales, L., and Keane, C, 2020b, COVID-19 Impacts to Geoscience Businesses (Summer-Fall 2020). American Geosciences Institute, Alexandria, US. https://www.americangeosciences.org/sites/default/files/ DB_2020-027_COVID-BusinessOperationsStaffing_Summer-Fall2020.pdf [accessed 2nd January 2021].

Gonzales, L., Poteracke, L., and Keane, C, 2020, COVID-19 Impacts to Small Businesses in the Mining and Oil and Gas Sectors. American Geosciences Institute, Alexandria, US. https://www.americangeosciences.org/sites/default/files/DB_2020-015-COVID-SBPS-211212213subsectors.pdf [accessed 2nd January 2021].

GSL, 2020, Geoscience for the future. Geological Society of London. https://www.geolsoc.org.uk/geoscienceforthefuture [accessed 26th June 2020].

Hahn-Griffiths, S., 2019, Digging into the Reputation of Mining Industry. Future of Mining Americas Conference 2019, Reputation Institute. https://www.reptrak.com/ [accessed 2nd December 2020].

IEA, 2020, World Energy Investment 2020 - Fuel supply. International Energy Agency, Paris. https://www.iea.org/reports/world-energy-investment2020/fuel-supply\#abstract [accessed 4th December 2020].

ILO, 2020a, An employers' guide on working from home in response to the outbreak of COVID-19. International Labour Organization, Geneva, ISBN: 9789220322536 (web PDF), 33 p. https://www.ilo.org/wcmsp5/groups/public/---ed_dialogue/---act_emp/documents/publication/ wcms_745024.pdf [accessed 5th January 2021].

ILO, $2020 \mathrm{~b}$, Teleworking during the COVID-19 pandemic and beyond. A practical guide. International Labour Organization, Geneva, ISBN: 
978-92-2-032405-9 (web PDF), 47 p. https:/www.ilo.org/wcmsp5/ groups/public/---ed_protect/---protrav/---travail/documents/instructionalmaterial/wcms_751232.pdf [accessed 5th January 2021].

Intelligent Transport, 2020, COVID-19: Transport industry latest news and analysis. https://www.intelligenttransport.com/topic_hub/covid-19-transport-news-analysis/ [accessed 2nd December 2020].

Jamasmie, C., 2020, Miners need to adopt next-generation values to battle reputation crisis, says Anglo American boss. Mining.com, Glacier Media Group, https://www.mining.com/miners-need-to-adopt-next-generation-values-to-battle-reputation-crisis-says-anglo-american-boss/ [accessed 2nd December 2020].

Lacey, J., Malakar, Y., McCrea, R., and Moffat, K., 2019, Public perceptions of established and emerging mining technologies in Australia. Resources Policy, v. 62, pp. 125-135. doi:10.1016/j.resourpol.2019.03.018

Lee J., 2020, A Neuropsychological Exploration of Zoom Fatigue. Psychiatric Times (online). https://www.psychiatrictimes.com/view/psychological-exploration-zoom-fatigue, 03.11.2020 [accessed 2nd December 2020].

Le Quéré, C., Jackson, R.B., Jones, M.W., Smith, A.J.P., Abernethy, S., Andrew, R.M., De-Gol, A.J., Willis, D.R., Shan, Y., Canadell, J.G., Friedlingstein, P., Creutzig, F., and Peters, G.P., 2020, Temporary reduction in daily global CO2 emissions during the COVID-19 forced confinement. Nature Climate Change. v. 10, pp 647-653. doi:10.1038/s41558020-0797-x

Macrotrends, 2020, WTI Crude Oil Prices - 10 Year Daily Chart. Macrotrends LLC, Seattle. https:/www.macrotrends.net/2516/wti-crude-oilprices-10-year-daily-chart [accessed 4th December 2020].

Marone, E., and Bohle, M., 2020, Geoethics for Nudging Human Practices in Times of Pandemics. Sustainability, v. 12, pp 7271. doi:10.3390/su12187271

McDonnell, D., Macknight E., and Donnelly, H., 2012, Co-operative Entrepreneurship: Co-operate for growth. Co-operative Education Trust Scotland, Glasgow, ISBN (Electronic), 978-0-9555342-4-9. https:// aura.abdn.ac.uk/bitstream/handle/2164/7699/Co operative Entrepreneurship_Co_operate_for_growth.pdf;jsessionid=E4211A9F159041293065 F4100F5A2339? sequence=1 [accessed 4th December 2020].

Panchal, N., Kamal, R., Orgera, K., Cox, C., Garfield, R., Hamel, L., Muñana, C., and Chidambaram, P., 2020, The Implications of COVID-19 for Mental Health and Substance Use. Published: Aug 21, 2020, Kaiser Family Foundation. https://www.kff.org/coronavirus-covid-19/issuebrief/the-implications-of-covid-19-for-mental-health-and-substance-use/ [accessed 4th January 2021].

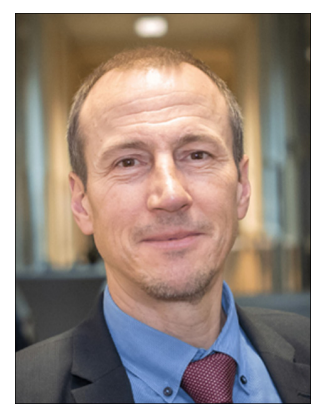

Marko Komac Independent consultant and EFG President, Ljubljana, Slovenia (and Brussels, Belgium).

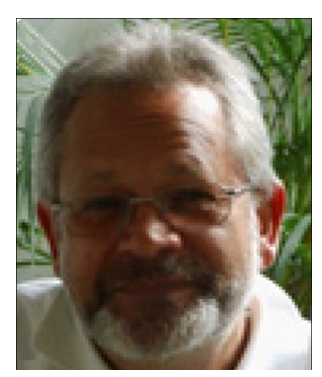

Michael Neumann Independent consultant (retired), Meggen, Germany.
Pankowska, M., 2020, Szumowski krytykuje UE: „Nie ma tej europejskiej solidarności”. To wielopiętrowy fałsz. OKO.press. https://oko.press/szumowski-krytykuje-ue-nie-ma-tej-europejskiej-solidarnosci-to-wielopietrowy-falsz/, 20.03.2020 [accessed 20th June 2020].

Peppoloni, C., and Di Capua, G., 2020, Geoethics as global ethics to face grand challenges for humanity. Geological Society, London, Special Publications, 508. doi:10.1144/SP508-2020-146

PwC, 2017, We need to talk About the future of mining. PwC, https:// www.pwc.com/gx/en/energy-utilities-mining/assets/pwc-mining-transformation-final.pdf [accessed 2nd December 2020].

Rystad Energy, 2020, Upstream Oil and Gas Investment Crashes To 15Year Low. Rystad Energy, Oslo. https://oilprice.com/Energy/EnergyGeneral/Upstream-Oil-Gas-Investment-Crashes-To-15-Year-Low.html [accessed 4th December 2020].

The Conversation, 2020, Articles on Green New Deal. The Conversation Trust (UK) Limited. https://theconversation.com/uk/topics/green-newdeal-40625 [accessed 3rd January 2021].

Vasconcelos, C., and Orion, N., 2021, Earth Science Education as a Key Component of Education for Sustainability. Sustainability, v. 13, pp 1316. doi:10.3390/su13031316 [accessed 31st January 2021].

WHO, 2020, World Health Organisation Coronavirus disease (COVID-19) pandemic web page. World Health Organisation. https:/www.who.int/ emergencies/diseases/novel-coronavirus-2019?gclid=CjwKCAjwxLH3BRApEiwAqX9arYNIeZR94ScY5RzZ1OClA3TYZrErIjW-smSGStIKSdVbcVEzGiteWBoCQikQAvD_BwE [accessed $31^{\text {st }}$ January 2021].

Zalasiewicz, J., 2020, How COVID-19 will look to geologists of the future. World Economic Forum, https://www.weforum.org/agenda/2020/08/ what-will-covid-19-look-like-to-geologists-in-the-far-future/ [accessed 2nd January 2021].

Zhang, J., and Hayashi, Y., 2020, Impacts of COVID-19 on the transport sector and measures as well as recommendations of policies and future research: Analyses based on a world-wide expert survey (May 27, 2020), 36 p. https://ssrn.com/abstract=3611806 [accessed 2nd December 2020].

Zhu, N., Zhang, D., Wang, W., Li, X., Yang, B., Song, J., Zhao, X., Huang, B., Shi, W., Lu, R., Niu, P., Zhan, F., Ma, X., Wang, D., Xu, W., Wu, G., Gao, G.F., and Tan, W., 2019, China Novel Coronavirus Investigating and Research Team. A Novel Coronavirus from Patients with Pneumonia in China 2019. New England Journal of Medicine, v. 382, pp. 727733. doi:10.1056/NEJMoa2001017

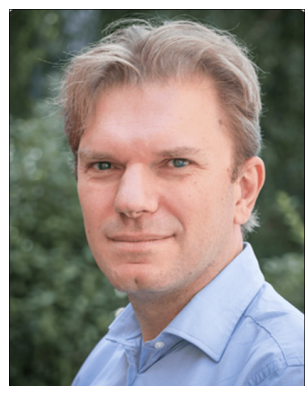

Glen Burridge Executive Director, European Federation of Geologists, Brussels, Belgium.

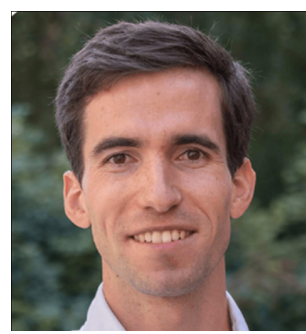

Tamas Miklovicz European Federation of Geologists, Brussels, Belgium. 


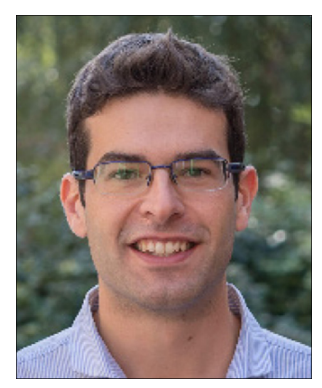

Alberto Sánchez Miravalles European Federation of Geologists, Brussels, Belgium.

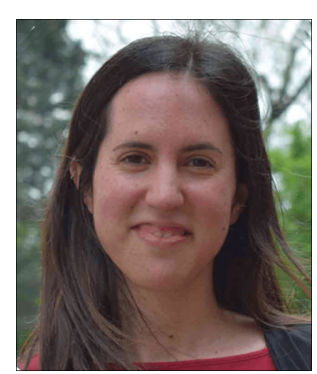

María A. López European Federation of Geologists, Brussels, Belgium.

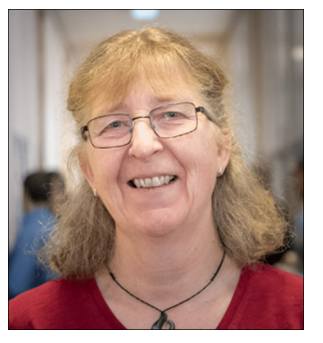

Ruth Allington Collaborative Problem Solving Ltd, EFG past President, current EFG Treasurer, Gerrards Cross, United Kingdom. 